\title{
Recognizing Balanced Diets for Children
}

\author{
Nurul Ridhi Utami ${ }^{1 *}$, Endang Mulyatiningsih ${ }^{2}$, and Nurul Ridha Utami ${ }^{3}$ \\ ${ }^{1}$ Mechanical Engineering Education Department, Graduate Studies, Yogyakarta State \\ University, Indonesia \\ ${ }^{2}$ Lecturer of the Faculty of Civil, Yogyakarta State University, Indonesia, Family \\ Welfare Education, Yogyakarta State University, Indonesia \\ ${ }^{3}$ Art Education, Graduate Studies, Yogyakarta State University, Indonesia \\ "nurulridhiutami@gmail.com
}

\begin{abstract}
The objectives of this study are (1) to describe adequate diets that children can have, (2) to explain knowledge about diets for children, and (3) to find out various types of diets for children. This research used a descriptive-qualitative research method. The data collection was undertaken through data observation. The results of this study show that some informants do not know various types of diets for children and some respondents' informants apply diets that nutritional counselors have provided. In short, it is necessary to consider balanced intakes and eating patterns to avoid obese or skinny children. If there is an overweight child, apply a low-energy diet or a dietary balance, and a skinny child can apply a High Protein and High Energy Diet (HPHED).
\end{abstract}

Keywords: Diet, Overweight, Lack of body weight, Child

\section{Introduction}

Everyone wants children to stay healthy, especially those who have become parents. Children are healthy both mentally and physically. Clinical nutrition specialist at the Tangerang General Hospital (RSUD), Dr. Dian Permatasari, Sp.GK highlights that children's ideal growth and development are appropriate for certain ages and children's health is mainly concerned with several characteristics. One of them is physical health along with some indicators to ponder, namely, a child has clear and clean eyes, shiny hair, fresh lips, and energy in doing every activity. Psychologically, according to the Indonesian health department, healthy children's souls develop naturally, their minds get smarter, their feelings become more sensitive and their willingness to socialize is better than other children.

In fulfilling and ensuring the nutrients, children need a dietary balance to help them grow. Problems arise when children experience growth. A striking problem that many parents face is a disruption of growth in children. This problem emerges in children who end up experiencing obesity and emaciation. Parents should avoid this problem so that their children can grow well [1].

Every parent will try to provide good foods and drinks to help children grow optimally. Good nutrition will make children energetic to develop social skills with peers and other people. The desire to see healthy children makes every parent obey whatever their children

Article History:

Received (January 31, 2020), Review Result (March 2, 2020), Accepted (April 8, 2020) 
want starting from food, drinks, snacks, and so forth. As a result, parents do not have control over maintaining their children's food and drink intake. This is because the child's appetite is good and is imbalanced with the diet and nutrition needed so the child is overweight or obese [2]. Then, what if the child is too thin?

The deformity is a sign in children have problems processing nutrients in the body. However, this does not become an accurate benchmark because each child has a different weight and length at birth, so say thin, each child is different. Children undergoing emaciation have the following characteristics: skin is less tight, nails experience initial fragility, pale eyes, mouth thrush, and dull hair.

Several causes make a child experience emaciation, one of which is the difficulty of feeding or eating. According to Fimele Famely on Kapanlagi.com, the causes of eating disorders include physical illness, changes in diets, or psychological problems. Other problems arise, namely gastrointestinal function disorders, skin disorders, and so on. For this reason, parents should take care of their children who experience developmental disorders like TB and genetic diseases in the family storyline. These concerns will increase if the child is shorter than his peers, the weight does not increase, and so forth. In addition, children will also experience a disruption of self-confidence with themselves resulting in fewer adjusted behaviors to their environment. As previously reviewed, children are healthy if their growths and developments are in line with their ages. To make children's nutrients better for the body, parents' sufficient knowledge about adequate nutrition for children is required. Not excessively, however, intense efforts are needed to encourage overweight or obese children to become thin because the children's diet is strongly regulated, so their lack of nutrition results in emaciation. If things happen, what parents need to do is to start a balanced diet for their children in a way that is based mainly on guidelines. Therefore, the author considers the title "Recognizing Adequate Diets for Children" to explain the solution that can be used as a reference for readers.

The rest of this paper is organized as follows. Section 2 describes the discussion. Section 3 describes the nutrients in the body. Finally, Section 4 concludes this work and follows by suggestion.

\section{Discussion}

People become obese by consumption of excess calories, the imbalance between calories intake and calories outgoing, leading a sedentary life, lack of sleep, disturbances in lipid metabolism, and intake of medications that put on obese. After 1 year, mainly the HP effects were maintained. Putative genes have been identified that suggest this diet to be particularly effective in $67 \%$ of the population. In conclusion, the DioGenes diet is effective in the prevention of weight regain and for weight reduction in overweight children under ad libitum conditions [3]. In an international journal of nursing sciences Syahrul's research write, The lowest intake of calcium was found in children of the normal group, whereas no significant difference in calcium intake was observed between underweight and overweight children. In addition, no significant differences in the intake of ferrum, vitamin $\mathrm{C}$, and vitamin $\mathrm{A}$ were observed among the three groups [4].

\subsection{Diets for obese children}

Obesity in children usually occurs because of uncontrolled intake of food, irregular eating patterns, and a less mobile body. The excess food fat is stored into fat in the children's bodies. To overcome obesity in children, children can go on a diet controlled by parents and a 
nutritionist. On kompas.com, Sari's mother shares an opinion about the principle of a good diet for children, namely the dietary principle of keeping balance with the diet or eating varied foods with portions according to the body's needs. The way to do it is to consume complex carbohydrates, reduce fat/fried consumption, avoid sweet foods, add portions of fruits and vegetables, and increase activities for children by at least 60 minutes per day. A study conducted by Khory Afifah Iriantika and Ani Margawati in [5] shows that the change would be better in the attitude and behavior of eating choices after nutritional counseling. Diet in terms of food groups (e.g., fruit and vegetables) or its content of a single nutrient (e.g., dietary fat or fiber) or single food could have been related to overweight/obesity, the relationships could not reflect human diets complexity, high correlations between intakes of various nutrients or food items and various nutrient-to-nutrient biochemical interactions and overweight/obesity [6]. In addition, children can have a low-energy diet, that is, a diet whose energy content is below normal requirements, adequate vitamins and minerals, and more fibers useful for the process of weight loss [7]. Children are suggested to take foods low in simple carbohydrates and fats such as cakes, snacks, and fried foods. However, the children have enough minerals, vitamins, and fiber. Besides, parents provide children with fruits and vegetables. The social practices of food choice that contributed to the formation of proper nutritional status of children under five years of age were (1) Monitoring children's intake of healthy food, (2) Ensuring that children ate and used food services, which contributed to the increased frequency of fruit and vegetable consumption, (3) Creating dishes and snacks, which contributed to reduced consumption of snacks that are high in sugar and carbohydrates and (4) Forming appropriate food choices [8].

The general cause of obesity is if we eat more than the body needs with a less mobile body. The excess of this food will be converted and stored into fat in our bodies. His advice for overcoming obesity in children: The principle of keeping a balanced diet or eating varies with portions according to body needs, with a note of consuming complex carbohydrates, reducing fat/fried foods, avoiding sweet foods, adding portions of fruits and vegetables on the ananda menu and increase physical activity to a minimum of 60 minutes per day. Children are recommended to eat snacks between meals, preferably healthy snacks such as dairy products, fruits, and vegetables, while children should be discouraged from eating fast foods as a meal since they may then eat a large amount of fast food rather than eating fast food as a snack. Thus, diet and exercise programs similar to obesity control programs could help reduce underweight among elementary school children [9]. Reducing energy input What is recommended is: Choosing a filling meal (choose a full meal: brown rice, whole wheat bread, and side dishes and vegetables. (Keep in mind: side dishes or food sources of protein and vegetables have a longer filling effect so children are not easily hungry) Consume more complex and high-fiber complex carbohydrates (whole wheat bread, brown rice, oats), and consume lots of vegetables and fruits for sources of vitamins, minerals, and fiber and satiate. Eating regularly according to schedule, given in small portions. healthy: cut fruit (papaya, pier, apple, melon, mango, grape). Choose low-fat milk. Include children in choosing and preparing food. Choose cooking techniques that do not add fat by steaming, boiling, roasting, or stir-frying. Whereas, which should be avoided or restricted, namely: Foods that are fried or fatty, set aside fat or fat on meat and chicken skin because of high fat. Coconut foods because they contain high fat. Don't use margarine to spread bread. Do not consume fast food or fast food because it is usually high in fat and calories. Do not consume sugary and sweet foods because they are high in calories and make children hungry fast for example snacks or snacks that have high energy but low nutrition (donuts, french fries, potato/cassava chips). Sugar, sweet foods, and sweetened condensed milk Increase energy output with physical activity, 
such as inviting children to play outside the house, walking, playing football, and playing on bicycles to burn fat on their bodies. Reducing relaxing activities: reduce watching TV and playing games. Engaging the family in activities - swimming, cycling, and walking in the morning with the family. The recommended food the children can consume is a balanced diet viewed from carbohydrates, namely brown rice, wheat bread, oats, and so forth. In terms of minerals and vitamins, children can eat papayas, pears, apples, melons, grapes, and so on. As for the fat supply, children can take low-fat milk. In kompas.com, Sari argues that balanced nutritional patterns determine the consumption of varied foods and appropriate portions. As a guide, the number of nutritional adequacies for Indonesian children on average aged 4-6 years old, nutrients data is described as follows.

- Energy: $1.550 \mathrm{kcal}$

- Protein: 39 grams

- Calcium: mg

- Iron: $9 \mathrm{mg}$

The feeding guide takes into account $3 \mathrm{~J}$ and $1 \mathrm{~A}$, namely:

The amount according to the portion of the children's needs

- Various types of foods

- $\quad$ Schedule large meals 3 times a day and 2-3 times healthy snacks

- Safe from chemicals such as artificial dyes, bleach, and preservatives

How Children Can Gain Weight Healthily. Whatever the reason, some general tips for healthy weight gain can include:

\subsection{Not skipping meals}

Considering eating four or five small meals a day, instead of trying to eat three bigger meals, since your child likely won't eat all of them anyway. Encouraging one or two regular healthy snacks each day. Avoiding low-nutrient, energy-dense foods, such as junk foods with empty calories, including candy, chips, and soft drinks. Eating high-nutrient, energy-dense foods, which are high in calories, but also have vitamins, minerals, and other nutrients, such as whole milk, yogurt made with whole milk, peanut butter, etc.

Avoiding low-energy or non-energy-containing drinks, such as diet soda and fruit drinks. Limiting drinks at mealtimes, so that your child doesn't fill up and may want to eat more food. Consulting a registered dietician for extra help, especially if your child has malabsorption or a chronic illness causing him to be underweight. Foods with a good amount of protein and fat and other nutrients in a small package, such as Whole milk or $2 \%$ milk, Cheese or yogurt made with whole milk or $2 \%$ milk, Fried eggs, Peanut butter, Cereal with whole milk, Orange juice, Trail mix with dried fruit, seeds, and nuts. You might also make a list of the foods that your child likes to eat and then try to find more nutrient-dense and energy-dense versions of those foods. This should include fruits and vegetables and a variety of foods from all of the food groups.

\subsection{Supplements to gain weight}

Although nutrition experts usually don't recommend giving kids supplements to help them gain weight, it can often help to supplement the food they are eating and drinking with extra calories, such as by adding the following nutrient-dense foods to certain other foods: Powdered milk, Margarine, Cheese, Wheat germ, Peanut butter, Instant breakfast mix, Honey, 
Avocados, Sour cream, Mayonnaise, Salad dressing. For example, adding 1 to 2 tablespoons of powdered milk to 8 ounces of whole milk (150 calories) can add an extra 30 to 60 calories to your child's glass of milk. Or you could add a packet of Carnation Breakfast Essentials to a glass of whole milk and add an extra 130 calories to that glass of milk for a total of 280 calories [10]. Based on DR. Sunita Almatster's research in [6], a low-energy diet aims to achieve and maintain the nutritional status according to age, gender, and physical needs; achieve a normal BMI of $18.5-25 \mathrm{~kg} / \mathrm{m} 2$ and reduce the energy intake, so that children lose weight. Requirements for a low-energy diet include energy, protein, fat, carbohydrates, vitamins, and minerals (DR. Sunita Almatster, in [7], elaborated below.

- Low energy is intended to lose weight. The reduction is managed in stages by considering eating habits and quality aspects of the quantity. To reduce weight by 12$2 \mathrm{~kg} / \mathrm{week}$, the energy intake should be reduced by 500-1000 kcal / day and it is a normal requirement. The calculation of normal energy requirements is based on the ideal body weight.

- Protein is slightly higher, which is $1-1 / 5 \mathrm{~g} / \mathrm{kg} /$ pound/day or $15 / 20 \%$ of total energy requirements.

- Medium fat is $20-25 \%$ of total energy requirements. Try a source of fat from highpolyunsaturated fats.

- Carbohydrate is slightly lower, 55-65 of the total energy requirements. Use more complex carbohydrates to provide satiety and prevent constipation. Can use sugar as a substitute for simple sugar.

- Vitamins and minerals are sufficient according to needs.

- It is recommended to eat 3 times and 2-3 times interlude.

- $\quad$ Sufficient liquid, i.e., 8-10 glasses/day.

Foods that must be avoided or restricted to children during the obesity diet are fried or fatty foods such as chicken meat or skin, coconut milk that have high fat, and sugary and sweet foods that are high in calories. The first key finding was that about one-third of mothers of low-income 4- to 8-year-old children expressed concern that their child doesn't or might not eat enough. Analysis of mothers' elaboration of this concern through qualitative analysis revealed a focus on inadequate quantity of intake, but with links made to the child being "too skinny", "picky", consuming insufficient vitamins, protein, fruits, and vegetables, or wasting food [11]. In addition, increasing activities outside the home such as running, walking, playing football, and others encourage children to move more for more sweat, so that children get healthier.

\subsection{Diets for thin children}

In the kompas.com, Dr. Widodo Udarwanto SpA [12] explains that the growths and developments of children are health problems useful to consider early. The growth failure or failure to thrive often occurs at the age of 6 months, and it is not detected properly. This disorder emerges in the form of malnutrition and lack of iron, calcium, minerals, vitamins, and so on. This is influenced by the quality and amount of calorie intake in children. To meet the energy and protein needs of the body, children can carry out a high-protein energy diet. This is intended to prevent and reduce damage to body tissues. In addition, it is important to 
gain weight to reach a normal body weight. In DR. Sunita Almatster's research in [7], a HighProtein High-Energy (HPHE) diet is a diet containing energy and protein above normal requirements. This diet is given to children in terms of ordinary food and added high-protein food ingredients such as milk, eggs, meat, and so forth. Depkes in [13] "Diets for underweight children are given to adolescents 6-18 years of age who are malnourished, namely weight and height that are not according to their age." Achieve ideal body weight and help with nutrients that require protein and calories high, food that meets balanced nutrition, type, and composition of foods that are suitable for the age and taste of individuals, using natural and self-processed ingredients. Various diets. A diet with weight cannot be done with the right diet. First, eat small portions and often. In addition, it provides an interesting variety of foods so that children have a good interest in eating Second, eat enough vegetables and fruit, lots of minerals and eat nutrient-rich foods. Food tips that are recommended for lessweight diets. Sources of charcoal hydrates: rice, porridge, bread, wheat, corn, potatoes, cassava, and others. Sources of protein can be obtained from animal protein and vegetable protein. Animal protein, namely: meat, chicken, eggs, fish, shellfish, shrimp, squid, and others. Vegetable protein can be obtained from tempeh, tofu, green beans, kidney beans, soybeans, and others. In addition, vegetables that contain vitamins and minerals can be obtained from kale, cabbage, cauliflower, and others. Sources of vitamins, fruits, or fruit juices are also needed by the body and are obtained from oranges, papaya apples, melons, guava, and others. Sources of fat are obtained from oil, coconut milk, margarine, and others. Additional as a complement to food is obtained from fresh milk, full cream milk, yogurt, ice cream, and others. Then foods that should be avoided by someone who needs a low-weight diet, less clean snacks can cause diarrhea, and drinks that contain alcohol or contain soda can cause children to fill up quickly. On the solusisehatku.com page, Desi Sintia Kresnawati gives insights into several ways that can help parents gain their children's weight. It turns out that it is important to eat healthy heart fat, make a diet plan, give children a snack or smoothies snack, and reduce giving children fast food, as stated below.

\subsubsection{Eating healthy heart fat}

Eating healthy heart fat can add calories to increase body weight such as butter, avocado, and nuts good for children's bodies.

\subsubsection{Making a diet plan}

Making a diet plan is effective for children to eat and it will be more fun if children get involved in making foods so that children know what and how foods are processed and managed to consume. Moreover, parents become aware of what foods children like, so that they are more excited when eating and make children have a happy and relaxed mood.

\subsubsection{Giving children a snack or smoothies snack}

Calories in shakes and smoothies are very high with a mixture of fresh milk, sugar, and fruit that make children enjoy these snacks without fear of being dangerous. Parents make sure that the ingredients in the foods they make are safe and nutritional. A mixture of strawberries, bananas, milk, chocolate, yogurt, and children's vegetables makes the children gain weight. 


\subsubsection{Reducing giving children fast food}

Keep in mind that fast food has high levels of salt, sugar, and saturated fats, so it is not good for children to consume. Junk food has empty calories which tend not to be good for children's health. It does not make the children fat and healthy, but they become thin and prone to illnesses.

DR. Sunita Almatster in [7] mentions the requirements of a high-protein high-energy diet, namely:

- High energy, 40-45 kcal / kg bw

- High protein, 2.0-2.5 g/ kg bw

- Adequate fat, $10-25 \%$ of total energy requirements

- Enough carbohydrates, the rest of normal needs

- Enough vitamins and minerals, according to normal needs

- Food is given in the form of digestibility

Having a high-protein high energy diet, children maintain a normal weight and enough appetite to consume a full meal.

\section{Nutrients in the body}

To support the needs required by the body, it takes the nutrients contained in the food. Examples of food are fish, eggs, rice, and so on. In general, foodstuffs has been containing nutrients, namely carbohydrates, proteins, fats, vitamins, and minerals. Substances that are required for good health are carbohydrates, proteins, fats, vitamins, minerals, and water. Carbohydrates, fat, protein, and vitamins are called organic substances (substances that contain carbon structure) while water is a mineral and inorganic substance.

Family environment with an emphasis on a parental role and strategies to improve children's eating behaviors; highlights early feeding experiences and later food choices; describes obesogenic environments, in particular, media inputs, as well as socioeconomic and educational status. All of these factors can influence the quantity of children's food intake, and food preferences, which contribute to dietary 'quality [14].

Energy is one of the glazed products of the metabolism of carbohydrates, proteins, and fats. Energy serves as energy substances for metabolism, growth, control of temperature, and physical activity [15]. These substances function as an energy source or energy (carbohydrates, protein, and fat), a source of a builder mainly to continue to grow and develop, and to replace cells damaged (proteins, fats, and vitamins), and a source regulator (vitamins, minerals, and water). Source regulating substances the body needs in small amounts is also called macro-nutrients, ie less than $100 \mathrm{mg}$ per day.

The body requires nutrients every day, namely: carbohydrates, proteins, fats, vitamins, minerals, fiber, and water plants.

(1) Carbohydrate

Carbohydrates are the main source of energy needed by the body. The body converts simple sugars and complex starches into glucose to be used as the energy source of the body's cells. Excess carbohydrates will increase weight because it is stored by the body as fat. Excess carbohydrates can lead to diseases such as obesity or being overweight or obese. However, it can be prevented by replacing the consumption of white rice with wheat/oatmeal, sorghum, quinoa, carrots, beets, and beans are high in fiber and full of vitamins, and minerals. That is because high-fiber carbohydrate sources make it more full, and full of nutrients. For example, $40 \%$ of calories come from carbohydrates. 
(2) Protein

Proteins are useful for growth and cell repair. However, excess protein is also not good for the body. Excess protein will typically suffer from gout, high cholesterol, weight gain, and others. Generally, the body needs protein $0.8 \mathrm{gr}$ of every $1 \mathrm{~kg}$ of body weight. Types of protein sources such as chicken, and fish or replace with vegetable proteins such as nuts, seeds, tempeh, and green vegetables.

(3) Fat

Fat is a rich source of energy that helps the absorption of vitamins A, D, E, and $\mathrm{K}$ and the formation of hormones in the body. The best fat sources are avocados, nuts, green vegetables, and fruits. Excess fat can make the body suffer from various diseases. Diseases resulting from excess fat, namely: increased risk of cancer, obesity, constipation, damage to the walls of arteries and brain, and high cholesterol. The average adult should consume $30 \%$ fat, $30 \%$ protein, and $40 \%$ carbohydrates.

(4) Vitamin

Vitamins can help increase metabolism and care for the body's cells. Each cell in the body requires vitamins for metabolism, and to maintain and replace damaged cells. But in food processing is a need for good handling so that vitamins are not damaged. Vitamin C and B Complex are very susceptible to temperature, so often break when cooked at high temperatures. Vitamin deficiency can cause diseases of the eye, anemia, hypertension, kidney disease, premature aging, eczema, cancer, cough, colds, osteoporosis, and pain when menstruation/menses. Vitamins can be found in fruits and vegetables such as spinach, apples, tomatoes, beans, avocado, beetroot, lemon, and orange.

(5) Mineral

Minerals are essential for the growth and metabolic processes in cells. Various members of the body require water intake, ranging from hair, skin, and bone to blood cells that need minerals in daily life. In addition, minerals also increased nerve function and help convert food into energy. Mineral deficiency can lead to many metabolic processes being interrupted and the resulting health problems such as osteoporosis, anemia, fatigue, dry skin, and hair loss until the problem is hormonal balance. Mineral idapatkan of plants that grow in the soil. For example, ginger, turmeric, carrot, beet, beans, cashews, and dark green vegetables such as kale.

(6) Fiber plants

Plant fibers, also called dietary fiber are part of the food that is not broken down by the body and help to keep the digestive system functioning better. Beneficial fiber helps the absorption of nutrients in the gut, maintaining optimum gut activity, controlling immunity and the balance of gut bacteria, and protecting body cells to prevent constipation, hemorrhoids, heart disease, and colon cancer. Tubuhan fibers can be obtained from the consumption of green vegetables such as spinach, celery, and other green vegetables. In addition plant fibers found in foods high in carbohydrates and protein also contains high levels of fiber such as wheat, sorghum, edamame, and tempeh.

(7) Water

Water must $65 \%$ of the body weight is made of water. The water content in the body is reduced through the digestive, and respiratory, sweat, and urine. The body needs to recharge the water content in its body by drinking mineral water or vegetable eating fruit that has a high water content such as cucumbers, watermelon, and grapefruit. Lack of water can cause 
irritation and damage to the cells and organs such as the brain, eyes, blood, and digestive tract. It is advisable to drink 8 glasses of water per day (2-3 liters).

(8) Magnesium and selenium

Magnesium and selenium are needed for the body to maintain a person's mood. Contained oysters, clams, sardines, and processed whole grains, such as oatmeal.

(9) Omega-3 fatty acids

Omega 3 dibutuhakan for brain growth. Omega-3 fatty acid deficiency can make someone advanced depression. This substance was found in fatty fish, such as mackerel, salmon, sardines, tuna, and beans.

(10) Antioxidants

Antioxidants serve to fight free radical damage that can affect brain function.

(11) Beta carotene

Beta carotene is required for the body and brain. Kandunagn the substance is present in apricots, broccoli, carrots, pumpkin, spinach, and sweet potatoes.

The combination according to the fulfillment of nutrients in the body, namely:

(1) Protein and fat

The combination of both of these foods becomes mismatched for not being given extra fat. For example, meat and beans are two types of food that have a combination of protein and fat. Elements of the fat contained in the food served to melamabatkan protein digestion to have enough time to interact with stomach acid. But if the existing fat is combined with other fat, such as meat fried in oil, automatically the fat contained in the oil will give extra fat in the meat, then, it could result in fat digestion in the stomach to be imperfect. Examples of foods with a combination of protein and fat are meat (chicken, beef, fish) roasted, baked, boiled, or steamed. Nuts are roasted, boiled, or steamed.

(2) Starch and fat

As well as in foods that contain protein and fat, starch and fat will be a combination of matching food to not giving extra fat in the process. For example, for sweet potatoes or yams, do not add coconut milk as when we make a compote. Use fats in moderation as a flavor enhancer. Examples of foods with a combination of starch and fat are:

(3) Bread with a little butter

- Mashed potatoes with a little cream

- $\quad$ Rice boiled with a little coconut oil

- The fries (protein and fat contained in the potato are very low, making it safe when fried with unsaturated oils and new, not used oil which is used).

(4) Sugar and acid

This combination is found in many fresh fruit and plain yogurt. Examples of foods with sugar and sour combinations are:

- Plain yogurt + pure honey.

- Plain yogurt + fruit sweet.

- $\quad$ Sour fruit + sweet fruit.

- Sweet and sour sauce.

- Vegetable fat and vegetable protein

Fat is a food component that serves as a medium for fat-soluble vitamins. Heating will give a sweet and savory smell as short-chain fatty evaporated stronger. If the heating is too high 
can produce cancer-causing free radicals. For example, the charred skewers from burning. Fat and protein in vegetables tend to be low, so it is safe when combining foods that both contain vegetable protein. Because the digestive process is not as heavy when we consume animal protein. Examples of foods with a combination of vegetable protein with vegetable proteins are brown rice + soybean, rice + red bean cakes, and soup content of various grains and legumes.

\section{Conclusion and suggestion}

\subsection{Conclusion}

Parents want children who are healthy, intelligent, and sociable with the environment well. Therefore, it is necessary to pay attention to the nutrient intake and pattern of eating habits of children to avoid being overweight or underweight. However, if children are overweight or underweight, they can have a balanced diet commonly called low-energy for fat bodies, and a high-energy high protein diet (HEHP) to maintain thin body postures.

\subsection{Suggestion}

It is expected that parents can pay attention to good food for children's consumption. It is better if children are given healthy food for their ideal health. This is a good step to avoid disruption of children's health and emotions so that their growths and developments undergo great progress considerably.

\section{Acknowledgments}

Authors wishing to acknowledge assistance or encouragement from colleagues, special work by technical staff, or financial support from organisasi should do so in an unnumbered acknowledgments section Immediately following the last numbered section of the paper.

\section{References}

[1] Peterson J. L. and Zill N., "Marital disruption, parent-child relationships, and behavior problems in children," Journal of Marriage and the Family, vol.86, no.2, pp.295-307 DOI: 10.2307/352397

[2] Bauer K. W., Yang Y. W., and Austin S. B., "How can we stay healthy when you're throwing all of this in front of us?" Findings from focus groups and interviews in middle schools on environmental influences on nutrition and physical activity," Health Education and Behavior, vol.31, no.1, pp.34-46, (2004)

[3] A Astrup, "The role of higher protein diets in weight control and obesity-related comorbidities," International Journal Of Obesity, vol.39, pp.721-726, (2015)

[4] Syahrul Syahrul, "Prevalence of underweight and overweight among school-aged children and its association with children's sociodemographic and lifestyle in Indonesia," International journal or nursing sciences, vol.3, pp.169-177, (2016)

[5] Devine C. M., Connors M., Bisogni C. A., and Sobal J., "Life-course influences on fruit and vegetable trajectories: qualitative analysis of food choices," Journal of Nutrition Education, vol.30, no.6, pp.361-370

[6] Min MU ect., "Dietary patterns and overweight/Obesity: A review article," Iran J Public Health, vol.46, no.7, (2017)

[7] Sunita Almatster, "Guide to the new edition of the diet "Rs.Dr.Cipto Mangunkusumo Nutrition Installation and the Indonesia Diestisien Association"," Gramedia, Jakarta, (2010)

[8] N.W. Prasodjo, "Research article food choice practices among underweight and normal-weight children under five years of age in west Java,” Indonesia. Pak. J. Nutr., vol.16, no.8, pp.588-598, (2017) 
[9] Gyu Young Lee, "Research article factors affecting underweight and obesity among elementary school children in South Korea," Asian Nursing Research, vol.9, pp.298-304, (2015)

[10] Pires C., and Agante L., "Encouraging children to eat more healthily: The influence of packaging," Journal of Consumer Behaviour, vol.10, no.3, pp.161-168, (2011)

[11] Anam Azam and Muhammad Shafique, "An overview of fruits and vegetables trade of China", International Journal of $\mathrm{u}$ - and e-Service, Science and Technology, vol.11, no.1, pp.33-44, (2018) DOI: 10.14257/ijunnesst.2018.11.1.03

[12] Field T., "Massage therapy facilitates weight gain in preterm infants," Current Directions in Psychological Science, vol.10, no.2, pp.51-54, (2001)

[13] Jennings A., Welch A., van Sluijs E. M., Griffin S. J., and Cassidy A., "Diet quality is independently associated with weight status in children aged 9-10 years," The Journal of Nutrition, vol.141, no.3, pp.453459, (2011)

[14] Saraswathi Sivamani, Saravana Kumar Venkatesan, Changsun Shin, Jangwoo Park, and Yongyun Cho. "Intelligent food control in a livestock environment," International Journal of Internet of Things and its Applications, vol.2. no.1, pp.1-6, (2018) DOI:10.21742/IJIoTA.2018.2.1.01

[15] Humayrah W., Hardiansyah H., Tanziha I., and Fahmida U., "Cluster analysis of food consumption patterns among women of reproductive age in Indonesia,” Jurnal Gizi dan Pangan, vol.14, no.3, pp.117-126, (2019) 
Recognizing Balanced Diets for Children

This page is empty by intention. 